\title{
Enhanced Photoluminescence Emission and Thermal Stability from Introduced Cation Disorder in Phosphors
}

\author{
Chun Che Lin, ${ }^{\dagger}$ Yi-Ting Tsai, ${ }^{\dagger}$ Hannah E. Johnston, ${ }^{\ddagger}$ Mu-Huai Fang, ${ }^{\dagger}$ Fengjiao Yu, ${ }^{\S}$ Wuzong Zhou, ${ }^{\S}$ \\ Pamela Whitfield, ${ }^{\&}$ Ye Li, ${ }^{\#}$ Jing Wang, ${ }^{\#}$ Ru-Shi Liu, ${ }^{*},, \|$ and J. Paul Attfield ${ }^{*} \dagger$ \\ 'Department of Chemistry, National Taiwan University, Taipei 106, Taiwan \\ *Centre for Science at Extreme Conditions and School of Chemistry, University of Edinburgh, King's Buildings, Mayfield \\ Road, EH9 3JZ Edinburgh, U.K. \\ ${ }^{\S}$ School of Chemistry, University of St Andrews, St Andrews, Fife KY16 9ST, U.K. \\ ${ }^{\&}$ Oak Ridge National Laboratory, Chemical and Engineering Materials Division, Oak Ridge, TN 37831 USA \\ \#MOE Key Laboratory of Bioinorganic and Synthetic Chemistry, State Key Laboratory of Optoelectronic Materials and \\ Technologies, School of Chemistry and Chemical Engineering, Sun Yat-sen University, Guangzhou, Guangdong 510275, \\ China
}

"Department of Mechanical Engineering and Graduate Institute of Manufacturing Technology, National Taipei University of Technology, Taipei 106, Taiwan

Supporting Information Placeholder

\begin{abstract}
Optimising properties of phosphors for use in white light-emitting diodes (WLEDs) is an important materials challenge. Most phosphors have a low level of lattice disorder due to mismatch between the host and activator cations. Here we show that deliberate introduction of high levels of cation disorder leads to significant improvements in quantum efficiency, stability to thermal quenching, and emission lifetime in $\mathrm{Sr}_{1.98-}$ ${ }_{x}\left(\mathrm{Ca}_{0.55} \mathrm{Ba}_{0.45}\right)_{\mathrm{x}} \mathrm{Si}_{5} \mathrm{~N}_{8}: \mathrm{Eu}_{0.02}(\mathrm{x}=0-1.5)$ phosphors. Replacing $\mathrm{Sr}$ by a $\left(\mathrm{Ca}_{0.55} \mathrm{Ba}_{0.45}\right)$ mixture with the same average radius increases cation size variance resulting in photoluminescence emission increases of $20-26 \%$ for the $\mathrm{x}=1.5$ sample relative to the $\mathrm{x}=0$ parent across the $25-200{ }^{\circ} \mathrm{C}$ range that spans WLED working temperatures. Cation disorder suppresses nonradiative processes through disruption of lattice vibrations and creates deep traps that release electrons to compensate for thermal quenching. Introduction of high levels of cation disorder may thus be a very useful general approach for improving the efficiency of luminescent materials.
\end{abstract}

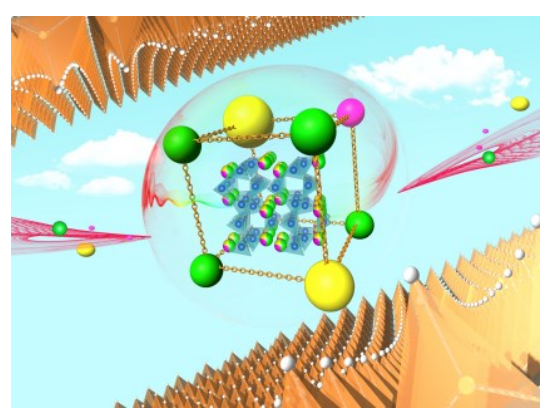

\section{INTRODUCTION}

White light-emitting diode devices (WLEDs) are an important low-energy alternative to traditional incandescent lamps and fluorescent light sources. ${ }^{1-4}$ WLEDs have advantages of low cost, easy fabrication, a tunable correlated colour temperature, and a high colour rendering index value. ${ }^{5,6}$ A blue LED chip $(440-470 \mathrm{~nm})$ is usually covered with one or more phosphors so that the combination of blue emission and longer-wavelength phosphor-converted radiation gives white light. ${ }^{7,8}$ Hence phosphors with high emission efficiencies that do not decrease at typical WLED operating temperatures of $150-200{ }^{\circ} \mathrm{C}$ are required. ${ }^{8}$ Nitridosilicates such as $\mathrm{M}_{2} \mathrm{Si}_{5} \mathrm{~N}_{8}: \mathrm{Eu}^{2+}(\mathrm{M}=\mathrm{Ca}, \mathrm{Sr}, \mathrm{Ba})$ are an excellent class of orange-red phosphors, showing high efficiency and high color purity under near-UV to blue light excitation, and thermal stability up to $200{ }^{\circ} \mathrm{C}$. $^{9-15}$ Moisture-induced degradation of $\mathrm{Sr}_{2} \mathrm{Si}_{5} \mathrm{~N}_{8}$ : $\mathrm{Eu}^{2+}$ phosphors has been minimised by adding a hydrophobic nanolayer formed by hydrolysis and polymerization of tetraethylorthosilicate and polydimethylsiloxane. ${ }^{16}$ Another approach was to add a passivating
$\mathrm{SrSiO}_{3}$ layer through thermally treatment in a $\mathrm{N}_{2}-\mathrm{H}_{2}$ atmosphere. These approaches are effective in reducing the thermaland moisture-induced degradation of PL properties in the red nitridosilicate phosphor. ${ }^{17}$ Chemical substitutions within a nitridosilicate host material can strongly affect the optical and thermal properties through changes in the local environment of the activator ions. For example, $\mathrm{M}_{1.95} \mathrm{Eu}_{0.05} \mathrm{Si}_{5-\mathrm{x}} \mathrm{Al}_{\mathrm{x}} \mathrm{N}_{8-\mathrm{x}} \mathrm{O}_{\mathrm{x}}(\mathrm{x}=$ $0-1)$ phosphors were found to have a red shift in emission wavelength and increased thermal stability with increasing AlO content $\mathrm{x}$ for $\mathrm{M}=\mathrm{Ba}$, but a blue shift and markedly decreased thermal stability were observed for $\mathrm{M}=\mathrm{Ca} .{ }^{18}$ This effect was attributed to cation-size mismatch between the $\mathrm{M}^{2+}$ host and $\mathrm{Eu}^{2+}$ activator cations. Substitutions of $\mathrm{Li}$ or $\mathrm{La}$ ions were found to tune the photoluminescence (PL) emission, thermal quenching, and decay time in the $\mathrm{CaAlSiN}_{3}:$ Eu phosphor through a neighbouring-cation substitution effect. ${ }^{19}$

Size mismatch between mixed cations, e.g. $\left(\mathrm{Sr}_{1-\mathrm{x}} \mathrm{Ca}_{\mathrm{x}}\right)$, tends to change lattice strain due to changes in the average ionic radius $\langle r\rangle$, and also introduces a disorder effect that may be quantified through the cation size variance $\left[\sigma^{2}=\left\langle r^{2}\right\rangle-\langle r\rangle^{2}\right] .{ }^{20,21}$ 
Average size and variance both change for such binary substitutions but mixtures of three or more cations may be used to vary $\langle r\rangle$ and $\sigma^{2}$ independently and separate their effects on materials properties. Previous studies in which $\langle r\rangle$ and doping level were held constant in series of ferromagnetic $\left(\mathrm{R}_{1}\right.$ $\left.{ }_{\mathrm{x}} \mathrm{M}_{\mathrm{x}}\right) \mathrm{MnO}_{3}$ perovskites, ${ }^{20}\left(\mathrm{R}_{2-\mathrm{x}} \mathrm{M}_{\mathrm{x}}\right) \mathrm{CuO}_{4}$ superconductors, ${ }^{22}$ and $\mathrm{MTiO}_{3}$ ferroelectrics ${ }^{23}$ (where $\mathrm{R}$ are trivalent lanthanides and $\mathrm{M}$ are divalent $\mathrm{Ca}, \mathrm{Sr}, \mathrm{Ba}$ ) revealed that their respective magnetic Curie, superconducting critical, and ferroelectric Curie transition temperatures all showed strong linear variations with $\sigma^{2}$.

To vary cation disorder within $\mathrm{M}_{2} \mathrm{Si}_{5} \mathrm{~N}_{8}: \mathrm{Eu}^{2+}$ phosphors we have taken the same approach by investigating here the series $\mathrm{Sr}_{1.98-\mathrm{x}}\left(\mathrm{Ca}_{0.55} \mathrm{Ba}_{0.45}\right)_{\mathrm{x}} \mathrm{Si}_{5} \mathrm{~N}_{8}: \mathrm{Eu}_{0.02}$. The $\left(\mathrm{Ca}_{0.55} \mathrm{Ba}_{0.45}\right)$ mixture has the same average cation radius as $\mathrm{Sr}^{2+}$, so the overall average $<r>$ for the $\mathrm{M}^{2+}$ cations is constant throughout, but the size variance $\sigma^{2}$ increases in proportion to $\mathrm{x}$. The resulting disorder effects are found to increase both the quantum efficiency $(\mathrm{QE})$ and thermal stability of the $\mathrm{Eu}^{2+}$ emission, with substantial improvements of up to $25 \%$ in overall PL emission for the disordered materials relative to the $\mathrm{x}=0$ parent. Cation disorder within the host lattice is thus shown to be both an important fundamental influence in phosphors and a useful tool for improving their performance in WLED devices.

\section{RESULTS AND DISCUSSION}

Sample Characterizations. $\mathrm{Sr}_{1.98-\mathrm{x}}\left(\mathrm{Ca}_{0.55} \mathrm{Ba}_{0.45}\right)_{\mathrm{x}} \mathrm{Si}_{5} \mathrm{~N}_{8}: \mathrm{Eu}_{0.02}$ samples with $\mathrm{x}=0,0.5,1.0,1.5$, and 1.98 were prepared and characterized as described in experimental methods. The $\mathrm{x}=$ 1.98 sample was found to be a multiphase mixture and was not explored further, but the other four samples were all orthorhombic $\mathrm{M}_{2} \mathrm{Si}_{5} \mathrm{~N}_{8}$-type materials with only small traces of secondary phases. Analysis results shown in Table 1 agree well with the nominal compositions of these materials. $\sigma^{2}$ was calculated using 10 -coordinate ionic radii $\left({ }^{10} r\right)$ for the $\mathrm{M}^{2+}$ cations, ${ }^{24}$ and increases from zero to a value of $\sigma^{2}=0.016 \AA^{2}$ at $\mathrm{x}=1.5$, equivalent to a substantial r.m.s. (root mean square) deviation of 0.12 $\AA$ in $\mathrm{M}^{2+}$ radius and hence in local $\mathrm{M}-\mathrm{N}$ distances.

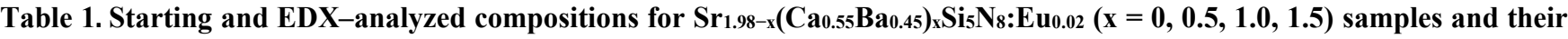
cation size variances.

\begin{tabular}{cccccc}
\hline$x$ & Starting composition & Analyzed formula & $\sigma^{2} / \AA^{2 b}$ & $\mathrm{External} \mathrm{QE} / \%$ & $\mathrm{Ea} / \mathrm{eV}$ \\
\hline 0 & $\mathrm{Sr}_{1.98} \mathrm{Si}_{5} \mathrm{~N}_{8}: \mathrm{Eu}_{0.02}$ & $\mathrm{Sr}_{1.98(1)} \mathrm{Si}_{4.9(2)} \mathrm{N}_{8}$ & 0.0000 & 48.7 & 0.21 \\
0.5 & $\mathrm{Sr}_{1.48} \mathrm{Ca}_{0.275} \mathrm{Ba}_{0.225} \mathrm{Si}_{5} \mathrm{~N}_{8}: \mathrm{Eu}_{0.02}$ & $\mathrm{Sr}_{1.48(3)} \mathrm{Ca}_{0.28(2)} \mathrm{Ba}_{0.22(1)} \mathrm{Si}_{4.9(2)} \mathrm{N}_{8}$ & 0.0052 & 53.4 & 0.24 \\
1.0 & $\mathrm{Sr}_{0.98} \mathrm{Ca}_{0.550} \mathrm{Ba}_{0.450} \mathrm{Si}_{5} \mathrm{~N}_{8}: \mathrm{Eu}_{0.02}$ & $\mathrm{Sr}_{0.98(3)} \mathrm{Ca}_{0.55(2)} \mathrm{Ba}_{0.45(1)} \mathrm{Si}_{4.9(2)} \mathrm{N}_{8}$ & 0.0104 & 55.9 & 0.26 \\
1.5 & $\mathrm{Sr}_{0.48} \mathrm{Ca}_{0.825} \mathrm{Ba}_{0.675} \mathrm{Si}_{5} \mathrm{~N}_{8}: \mathrm{Eu}_{0.02}$ & $\mathrm{Sr}_{0.47(3)} \mathrm{Ca}_{0.81(2)} \mathrm{Ba}_{0.70(1)} \mathrm{Si}_{4.9(1)} \mathrm{N}_{8}$ & 0.0156 & 58.5 & 0.32 \\
\hline
\end{tabular}

${ }^{a}$ Formulae are calculated by normalizing to $\mathrm{Ca}+\mathrm{Sr}+\mathrm{Ba}=1.98$; the Eu contents are fixed at 0.02 .

${ }^{b}$ Size variances are calculated using $10-$ coordinate cationic radii.

The $\mathrm{Sr}_{1.98-\mathrm{x}}\left(\mathrm{Ca}_{0.55} \mathrm{Ba}_{0.45}\right)_{\mathrm{x}} \mathrm{Si}_{5} \mathrm{~N}_{8}: \mathrm{Eu}_{0.02}$ samples $(\mathrm{x}=0,0.5,1.0$, 1.5) were characterized using synchrotron $X$-ray diffraction and powder neutron diffraction. Fits to the data for the $\mathrm{x}=0.5 \mathrm{sam}-$ ple are shown in Figure 1 and other data are shown in Supplementary Figures S1-4 and Supplementary Tables S1-4. The diffraction results demonstrate that the $\mathrm{x}=0$ to 1.5 materials adopt the orthorhombic $\mathrm{M}_{2} \mathrm{Si}_{5} \mathrm{~N}_{8}$ structure (space group $P \mathrm{mn} 2_{1}$ ). 298 $\mathrm{K}$ lattice parameters (Figure $1 \mathrm{~b}$ ) show irregular variations of less than $\pm 0.1 \%$ as $\mathrm{x}$ increases from 0 to 1.5 , confirming that the average unit cell and lattice strain remain constant across the series to a very good approximation. Powder neutron diffraction data were obtained from all samples in the temperature range $25-400{ }^{\circ} \mathrm{C}$ to check the thermal stability of these materials across WLED working temperatures $\left(150-200{ }^{\circ} \mathrm{C}\right)$. All of the samples show very similar thermal expansions across this range, with no structural changes and bulk thermal expansion coefficients of $15-20 \times 10^{-6} \mathrm{~K}^{-1}$.

Two inequivalent $\mathrm{M}$ cation sites are present in the orthorhombic $\mathrm{M}_{2} \mathrm{Si}_{5} \mathrm{~N}_{8}$ structure, as shown in the inset of Figure $3 \mathrm{a}$, and simultaneous refinements against $298 \mathrm{~K} \mathrm{X}$-ray and neutron data were used to estimate $\mathrm{Ca} / \mathrm{Sr} / \mathrm{Ba}$ cation occupancies at the two sites by making use of the different elemental scattering contrasts for X-rays and neutrons. The Eu dopant concentration was fixed at $1 \%$ for both sites. Results in Supplementary Table 3 show that the 10-coordinate M1 site tends to be more disordered with approximately equal amounts of $\mathrm{Ca}$ and Ba replacing $\mathrm{Sr}$ almost completely at $\mathrm{x}=1.5$, where the $\mathrm{M} 1$ size variance is $\sigma_{1}^{2}=0.020 \AA^{2}$. The M2 site is 8 -coordinate and so is slightly smaller, and is occupied predominantly by $\mathrm{Ca}$ and $\mathrm{Sr}$ with less $\mathrm{Ba}$, leading to a smaller $\sigma_{2}^{2}=0.011 \AA^{2}$ at $\mathrm{x}=1.5$. The $\mathrm{M}-\mathrm{N}$ bond distances reflect these trends as the M1-N distances show little variation across the series while the M2-N values decrease with $\mathrm{x}$ as shown in Figure 1d. Although the $\mathrm{Ca} / \mathrm{Sr} / \mathrm{Ba}$ populations and $\sigma^{2}$ values at the two sites differ, these diffraction results show that both sites are substantially disordered and there is no simple cation segregation as $\mathrm{x}$ increases.
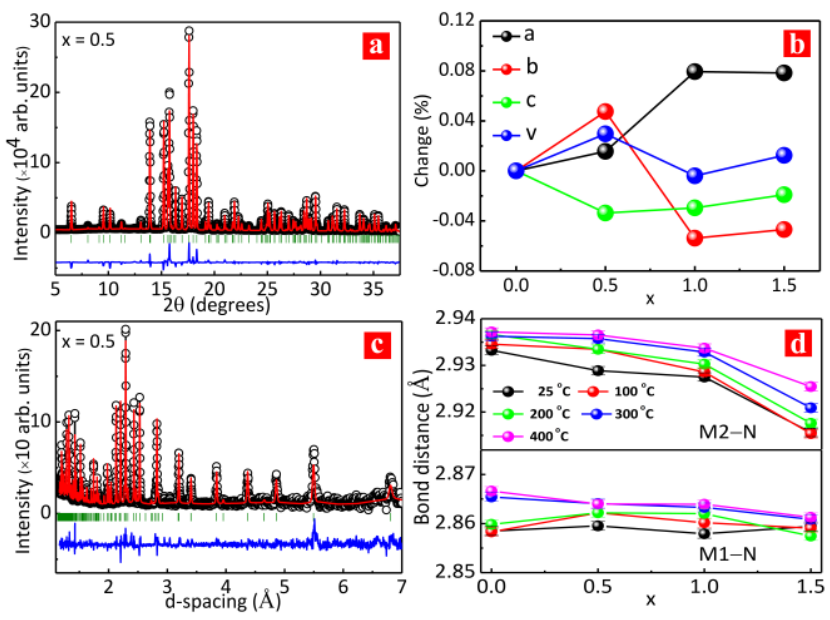

Figure 1. Crystal structure characterization of $\mathrm{Sr}_{1.98-\mathrm{x}}\left(\mathrm{Ca}_{0.55} \mathrm{Ba}_{0.45}\right)_{\mathrm{x}} \mathrm{Si}_{5} \mathrm{~N}_{8}: \mathrm{Eu}_{0.02}$ phosphors. (a) Rietveld fit to room temperature synchrotron XRD data $(\lambda=0.774907 \AA)$ for the $x=0.5$ sample. (b) Relative changes in the $298 \mathrm{~K}$ lattice parameters determined from fits to synchrotron XRD data as a function of x. (c) Fit to time-of-flight neutron diffraction data from the $\lambda=2.665 \AA$ bank at room temperature for the $\mathrm{x}=0.5$ sample. (d) Temperature and $\mathrm{x}$ dependence of $\mathrm{M}-\mathrm{N}$ bond distances from Rietveld refinements using the neutron data.

Raman spectra have been used to study the lattice vibrations of the $\mathrm{Sr}_{1.98-\mathrm{x}}\left(\mathrm{Ca}_{0.55} \mathrm{Ba}_{0.45}\right)_{\mathrm{x}} \mathrm{Si}_{5} \mathrm{~N}_{8}: \mathrm{Eu}_{0.02}$ materials as shown in 
Figure 2a. The peaks at 200-700, and 700-1,000 $\mathrm{cm}^{-1}$ respectively represent bending, and stretching modes of $\mathrm{SiN}_{2}$ or $\mathrm{SiN}_{4}$ groups, ${ }^{25,26}$ as shown in Figure 2a. Sharp vibrational peaks are observed for $\mathrm{x}=0$ but these broaden rapidly as $\mathrm{x}$ increases because of the bonding and mass disorder introduced by replacing $\mathrm{Sr}$ with $\mathrm{Ca}$ and $\mathrm{Ba}$. The $\mathrm{x}=1.0$ and 1.5 spectra are almost identical showing that the $\mathrm{Ca} / \mathrm{Sr} / \mathrm{Ba}$ coordinations around $\mathrm{SiN}_{2}$ or $\mathrm{SiN}_{4}$ have essentially become statistical for $\mathrm{x} \geq 1.0$. These spectra resemble that of a glass, although the materials remain crystalline as observed in the diffraction measurements.
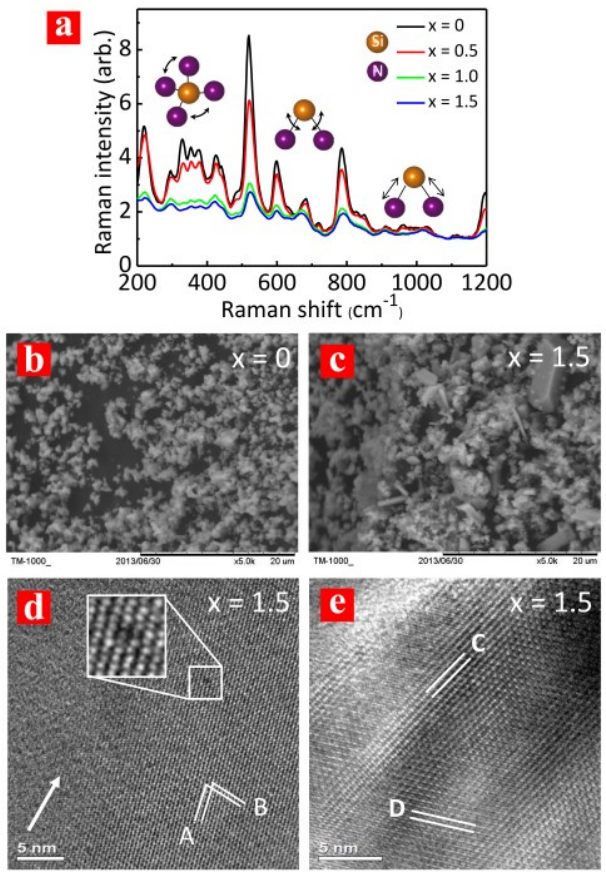

Figure 2. Lattice disorder and microstructural effects in $\mathrm{Sr}_{1.98-\mathrm{x}}\left(\mathrm{Ca}_{0.55} \mathrm{Ba}_{0.45}\right)_{\mathrm{x}} \mathrm{Si}_{5} \mathrm{~N}_{8}: \mathrm{Eu}_{0.02}$ phosphors. (a) Raman spectra of $\mathrm{x}=0,0.5,1.0$, and 1.5 samples with bending and stretching mode regions shown schematically. (b,c) SEM images of bulk $\mathrm{x}=0$ and $\mathrm{x}=1.5$ materials (scale bar, $20 \mu \mathrm{m})$. (d,e) Typical HRTEM images from the $x=1.5$ sample. (d) Image showing a large crystalline area at the right hand side, viewed down the [12-1] zone axis. Atomic planes A and B have d-spacings of 3.81 and $2.36 \AA$, corresponding to (012) and (202) layers of the orthorhombic $\mathrm{M}_{2} \mathrm{Si}_{5} \mathrm{~N}_{8}$ structure, respectively, with an interplane angle of ca. $65^{\circ}$. Another domain at the top left corner has a slightly different crystal orientation and the two domains intergrow well. However, the grain boundary between them indicated by the arrow is wide and blurry. Dark spots are apparent in the image contrast pattern, and the square marked area around one of these is expanded in the inset. Local lattice distortion characteristic of a point defect is visible. (e) HRTEM image of a region showing many domains. The d-spacings $\mathrm{C}$ and $\mathrm{D}$ are $4.82 \AA$, which indexed as (101) or (10-1) with an interplane angle of ca. $63^{\circ}$.

Effects of increasing chemical disorder have also been investigated by comparing electron microscopy (EM) images of $\mathrm{x}=$ 0 and $x=1.5$ samples. Scanning EM images in Figures $2 b$ and c show that $\mathrm{x}=0$ particles have fairly uniform sizes below $\sim 1$ $\mu \mathrm{m}$, but the $\mathrm{x}=1.5$ material has a more variable morphology including some large crystallites up to $\sim 10 \mu \mathrm{m}$ dimensions. High-resolution transmission EM (HRTEM) images and corresponding selected area electron diffraction (SAED) patterns such as those shown in Supplementary Figure S5 demonstrate that the $\mathrm{x}=0$ sample has large uniform, crystal domains with few observed defects. However, typical HRTEM images for the $\mathrm{x}=1.5$ sample in Figures $2 \mathrm{~d}$ and e show multidomain and defect features. Dark spots are evident in the image contrast pattern in Figure $2 \mathrm{~d}$ and the enlargement of one spot in the inset shows that a local lattice distortion is visible. This corresponds to the diffraction contrast from a point defect, as previously reported. ${ }^{27,28}$ Point defects in the $\operatorname{Sr}_{1.98-\mathrm{x}}\left(\mathrm{Ca}_{0.55} \mathrm{Ba}_{0.45}\right)_{\mathrm{x}} \mathrm{Si}_{5} \mathrm{~N}_{8}: \mathrm{Eu}_{0.02}$ samples most likely arise from atomic substitutions at $\mathrm{M}^{2+}$ sites due to the large differences in ionic size. Cation disorder also results in various domain structures, with a wide and blurry grain boundary observed in Figure 2d, and small domains with well-defined grain boundaries in Figure 2e. No decomposition was observed during the TEM studies, confirming their high thermal stability.

Luminescence Measurements. All of the $\mathrm{Sr}_{1.98}$ ${ }_{x}\left(\mathrm{Ca}_{0.55} \mathrm{Ba}_{0.45}\right)_{\mathrm{x}} \mathrm{Si}_{5} \mathrm{~N}_{8}: \mathrm{Eu}_{0.02}$ samples emit in the orange to red region when excited with UV or blue sources, like other $\mathrm{M}_{2} \mathrm{Si}_{5} \mathrm{~N}_{8}: \mathrm{Eu}^{2+}(\mathrm{M}=\mathrm{Ca}, \mathrm{Sr}, \mathrm{Ba})$ materials, and so are good phosphors for WLEDs applications. Figure 3 a shows the excitation and emission spectra which result from the $4 f^{7}\left({ }^{8} \mathrm{~S}_{7 / 2}\right) \leftrightarrow$ $4 f^{6}\left({ }^{7} \mathrm{~F}\right) 5 d^{1}$ transition of $\mathrm{Eu}^{2+}$. The excitation spectra broaden slightly with increasing disorder $(\mathrm{x})$ but do not otherwise change. However, the emission spectra excited at $460 \mathrm{~nm}$ show a substantial broadening and shift to longer wavelengths (a red shift) with increasing $\mathrm{x}$. The emission spectra were resolved into two peaks arising from $\mathrm{Eu}^{2+}$ at the two distinct crystallographic sites M1 and M2 as shown on Figure 3a, and derived parameters are in Supplementary Table 5 and are plotted in Figures $3 \mathrm{~b}$ and c. The Eu1 and Eu2 peaks show similar red shifts of $\sim 300 \mathrm{~cm}^{-1}$ as $\mathrm{x}$ increases from 0 to 1.5 while peaks become $\sim 300 \mathrm{~cm}^{-1}$ wider consistent with increasing lattice disorder. Lattice contraction (e.g. from $\mathrm{Ba}_{2} \mathrm{Si}_{5} \mathrm{~N}_{8}: \mathrm{Eu}^{2+}$ to $\mathrm{Sr}_{2} \mathrm{Si}_{5} \mathrm{~N}_{8}: \mathrm{Eu}^{2+}$ ) is known to result in red shifts of the emission, however the average lattice strain is approximately constant across the $\mathrm{Sr}_{1.98-}$ ${ }_{x}\left(\mathrm{Ca}_{0.55} \mathrm{Ba}_{0.45}\right)_{\mathrm{x}} \mathrm{Si}_{5} \mathrm{~N}_{8}: \mathrm{Eu}_{0.02}$ series.
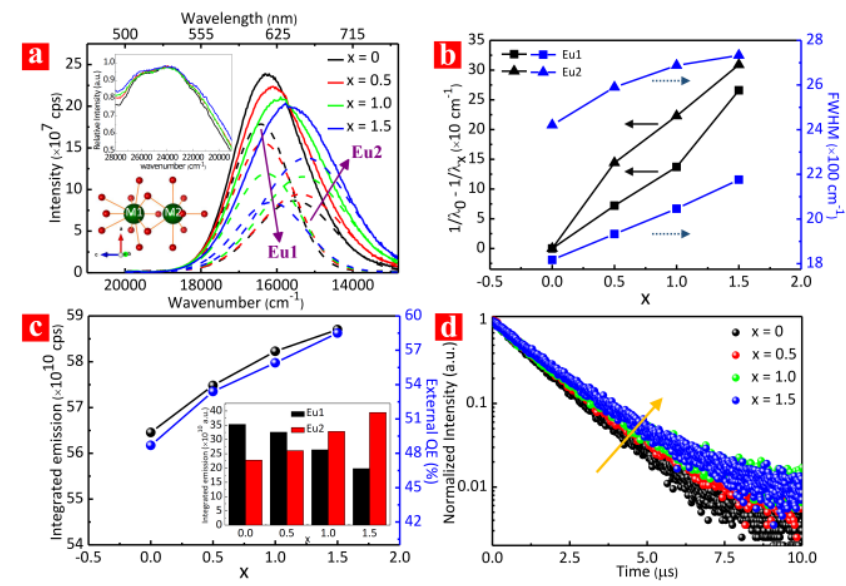

Figure 3. Photoluminescence (PL) properties of $\mathrm{Sr}_{1.98-\mathrm{x}}\left(\mathrm{Ca}_{0.55} \mathrm{Ba}_{0.45}\right)_{\mathrm{x}} \mathrm{Si}_{5} \mathrm{~N}_{8}: \mathrm{Eu}_{0.02}$ phosphors. (a) Excitation spectra (upper inset), normalized at the maximum emission wavelength, and emission spectra excited at $\lambda_{\mathrm{ex}}=460 \mathrm{~nm}$ at room temperature. The PL spectra are decomposed into Gaussian contributions from $\mathrm{Eu}^{2+}$ at the two cation sites in the orthorhombic $\mathrm{M}_{2} \mathrm{Si}_{5} \mathrm{~N}_{8}$ structure. Coordination environments for the M1 (10coordinate) and M2 (8-coordinate) atoms are shown in the lower inset. (b) Plot of the energy shift and Full Width at Half Maximum (FWHM) for the Eu1 and Eu2 peaks versus x. (c) Evolution of the integrated emission intensity and the quantum 
efficiency as $\mathrm{x}$ increases. The inset shows the individual integrated Eu1 and Eu2 emission intensities. (d) Luminescence decay curves at room temperature.

Hence the observed red shift of both Eu1 and Eu2 peaks suggests that the most efficient emission is from $\mathrm{Eu}^{2+}$ cations occupying smaller sites with the increasing range of sizes that become available as $\mathrm{x}$ rises. A marked shift of intensity from the Eu1 to the Eu2 emission is also observed with increasing $\mathrm{x}$, as shown in Figures $3 \mathrm{a}$ and $\mathrm{c}$. This shows that the $\mathrm{Eu}^{2+}$ activator cations tend to migrate from M1 to M2 sites with increasing $\mathrm{x}$. The $\mathrm{Eu}^{2+}$ dopants $\left({ }^{10} r=1.35 \AA\right)$ are much closer in size to $\mathrm{Sr}$ cations $(1.36 \AA)$ than to $\mathrm{Ca}(1.23 \AA)$ or Ba ions $(1.52 \AA)$. Hence the $\mathrm{Eu}^{2+}$ activators follow $\mathrm{Sr}^{2+}$ in the trends observed in the site occupancy refinements above, where $\mathrm{Sr}(\mathrm{Eu})$ and $\mathrm{Ca}$ preferentially occupy M2 sites at high $\mathrm{x}$, while M1 sites are occupied mainly by $\mathrm{Ba}$ and $\mathrm{Ca}$. Hence the proportion of $\mathrm{Eu}^{2+}$ ions at the M2 increases significantly with $\mathrm{x}$, as shown schematically in Supplementary Figure S6. A notable consequence of the introduced disorder is that the external quantum efficiency of the $\mathrm{Sr}_{1.98-\mathrm{x}}\left(\mathrm{Ca}_{0.55} \mathrm{Ba}_{0.45}\right)_{\mathrm{x}} \mathrm{Si}_{5} \mathrm{~N}_{8}: \mathrm{Eu}_{0.02}$ phosphors increases significantly, from $49 \%$ at $\mathrm{x}=0$ to $59 \%$ at $\mathrm{x}=1.5,{ }^{29}$ as shown in Figure $3 \mathrm{c}$ and Table 1 . The integrated emission spectra show the same trend. However, the external QEs of as-prepared $\mathrm{Sr}_{1.98-}$ ${ }_{x}\left(\mathrm{Ca}_{0.55} \mathrm{Ba}_{0.45}\right)_{\mathrm{x}} \mathrm{Si}_{5} \mathrm{~N}_{8}: \mathrm{Eu}_{0.02}(\mathrm{x}=0-1.5)$ phosphors are lower than those of commercial materials because of small particle size as illustrated in Supplementary Figure S7. Luminescence lifetimes also increase with disorder as shown in Figure 3d. The luminescence decays are described by single exponentials with time constants increasing from 1.3 to $1.5 \mu \mathrm{s}$ as $\mathrm{x}$ increases from 0 to 1.5 .

Another important aspect is the stability of the PL to thermal quenching, to ensure highly efficient WLEDs at working temperatures up to $200{ }^{\circ} \mathrm{C} .{ }^{30,31}$ Figure 4 a shows the temperature variation of the integrated $\mathrm{PL}$ for the $\mathrm{Sr}_{1.98}$ ${ }_{x}\left(\mathrm{Ca}_{0.55} \mathrm{Ba}_{0.45}\right)_{\mathrm{x}} \mathrm{Si}_{5} \mathrm{~N}_{8}: \mathrm{Eu}_{0.02}$ phosphors over the range $25-300{ }^{\circ} \mathrm{C}$. The fitted activation energies for quenching and given in Table 1 and show a substantial increase from $0.21 \mathrm{eV}$ at $\mathrm{x}=0$ to 0.32 $\mathrm{eV}$ at $\mathrm{x}=1.5 .^{32}$ Disorder thus enhances the thermal stability of PL, with the largest improvements in Figure 4a observed at $150-250{ }^{\circ} \mathrm{C}$ close to the working temperatures for WLED devices. The $\mathrm{x}=1.5$ material shows an emission loss of only $8 \%$ at $200{ }^{\circ} \mathrm{C}$. The combined effects of cation disorder in increasing quantum efficiency and suppressing thermal quenching are shown in Figure $4 \mathrm{~b}$. The improvement in photoluminescence relative to the $\mathrm{x}=0$ sample, $\Delta \mathrm{PL} / \mathrm{PL}$, increases with $\mathrm{x}$ in the $\mathrm{Sr}_{1.98-\mathrm{x}}\left(\mathrm{Ca}_{0.55} \mathrm{Ba}_{0.45}\right)_{\mathrm{x}} \mathrm{Si}_{5} \mathrm{~N}_{8}: \mathrm{Eu}_{0.02}$ series, with values of $20-26 \%$ for $\mathrm{x}=1.5$. Hence, the replacement of $\mathrm{Sr}$ by a $\left(\mathrm{Ca}_{0.55} \mathrm{Ba}_{0.45}\right)$ mixture to introduce lattice disorder in $\mathrm{M}_{2} \mathrm{Si}_{5} \mathrm{~N}_{8}: \mathrm{Eu}^{2+}$ phosphors results in a significant increase of PL emission over the range of WLED working temperatures. Thermoluminescence (TL) measurements (Figure 4c) have been used to investigate how disorder affects the temperature stability of $\mathrm{PL}$ in the $\mathrm{Sr}_{1.98-\mathrm{x}}\left(\mathrm{Ca}_{0.55} \mathrm{Ba}_{0.45}\right)_{\mathrm{x}} \mathrm{Si}_{5} \mathrm{~N}_{8}: \mathrm{Eu}_{0.02}$ materials. TL measures luminescence from trapped electrons that are released by increasing the sample temperature, as shown schematically in Figure 4d. The TL spectra reveal that emission from heating the parent $\mathrm{x}=$ 0 material has a single peak at $\sim 370 \mathrm{~K}$ corresponding to electrons in fairly shallow traps. The shallow trap peak remains at $350-400 \mathrm{~K}$ as $\mathrm{x}$ increases, but the intensity decreases greatly and high temperature emission peaks at 450-500 K become prominent. This demonstrates that increasing lattice disorder introduces a large number of deep traps. Release of the electrons from deep traps at $\sim 470 \mathrm{~K}$ WLED working temperatures results in increased emission that compensates for thermal losses due to nonradiative energy transfer. ${ }^{33}$ Hence formation of deeper traps due to cation disorder accounts for the increases of luminescence lifetime shown in Figure $3 \mathrm{~d}$ and of thermal quenching stability in Figure 4a with disorder.
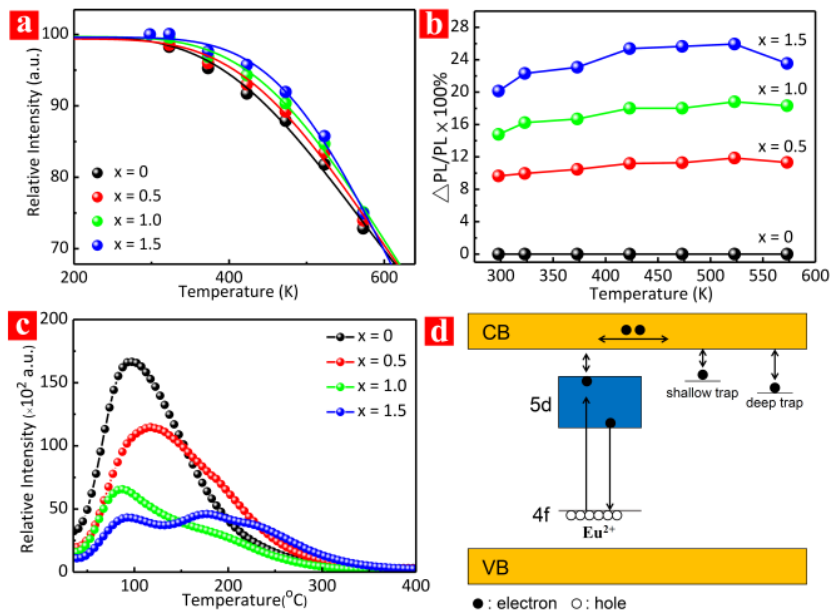

Figure 4. Thermal properties of $\mathrm{Sr}_{1.98-\mathrm{x}}\left(\mathrm{Ca}_{0.55} \mathrm{Ba}_{0.45}\right)_{\mathrm{x}} \mathrm{Si}_{5} \mathrm{~N}_{8}: \mathrm{Eu}_{0.02}$ phosphors. (a) Photoluminescence $(\mathrm{PL})$ intensity ratios $I_{\mathrm{T}} / I_{0}$ at temperatures $T=298-573 \mathrm{~K}$. The curves show fits of the equation $I_{\mathrm{T}} / I_{0}=\left[1+D \exp \left(-E_{\mathrm{a}} / k T\right)\right]$ ${ }^{1}$, where $I_{0}$ (intensity at $T=0$ ), $D$, and the activation energy $E_{\mathrm{a}}$ are refined variables. Fitted $E_{\mathrm{a}}$ values are shown in Table 1. (b) Increases in photoluminescence relative to the $\mathrm{x}=0$ sample, $\Delta$ $P L / P L$, as a function of temperature. These are calculated as $\Delta$ $P L / P L=\left(I_{x} / I_{x=0}\right)\left(Q_{x} / Q_{x=0}\right)-1$ where $Q$ is external quantum efficiency measured at $298 \mathrm{~K}$ and $I$ is emission intensity with thermal variations as shown in a. (c) Thermoluminescence (TL) spectra collected at $30-400{ }^{\circ} \mathrm{C}$. (d) Schematic energy diagram showing the TL mechanism for temperature-dependent emission. Electrons excited from $\mathrm{Eu} 4 f$ to $5 d$ states can be delocalized into the conduction band (CB) and captured by traps at lattice defects. Trapped electrons may be released by thermal excitation to the $\mathrm{CB}$, and return via the $5 d$ state, to the $4 f$ ground state with light emission. Electrons in shallow traps are released at near-ambient temperatures, whereas high temperatures are needed to release electrons from deep traps.

Discussion. The results demonstrate that $\mathrm{Sr}_{1.98-\mathrm{x}}\left(\mathrm{Ca}_{0.55} \mathrm{Ba}_{0.45}\right)_{\mathrm{x}} \mathrm{Si}_{5} \mathrm{~N}_{8}: \mathrm{Eu}_{0.02}$ phosphors remain highly crystalline to powder X-ray and neutron diffraction when substantial cation size disorder is introduced. Disorder effects are observed in the microstructure where smaller domains and point defects are observed by HRTEM, and the Raman peaks are substantially broadened. PL performance is enhanced substantially despite the formation of deep electron traps in the disordered materials. Both the QE and the stability of the PL to thermal quenching are found to increase with $\mathrm{x}$ in the $\mathrm{Sr}_{1.98-\mathrm{x}}\left(\mathrm{Ca}_{0.55} \mathrm{Ba}_{0.45}\right)_{\mathrm{x}} \mathrm{Si}_{5} \mathrm{~N}_{8}: \mathrm{Eu}_{0.02}$ series. The increase in external QE may be attributed to local distortions of the coordination environments around $\mathrm{Eu}^{2+}$, which tend to break the internal symmetry of the polyhedra. The increase in particle size observed on comparing $\mathrm{x}=0$ and $\mathrm{x}=$ 1.5 samples by SEM is also likely to contribute so the increase in QE may be a materials-specific effect. The improved stability of the PL to thermal quenching is an important effect that can be directly attributed to the lattice disorder. Nonradiative decay occurs through multiphonon relaxation, and this is disrupted if 
phonons are trapped or scattered by disorder. The Raman spectra show that the lattice vibrational peaks are broadened and suppressed for $\operatorname{Sr}_{1.98-x}\left(\mathrm{Ca}_{0.55} \mathrm{Ba}_{0.45}\right)_{\mathrm{x}} \mathrm{Si}_{5} \mathrm{~N}_{8}: \mathrm{Eu}_{0.02}$ Samples with $\mathrm{x}>$ 1 , and this reduces the efficiency of energy transfer to the lattice. Hence the use of crystalline host materials, to preserve long range structural order and rigidity, but with internal disorder introduced to suppress nonradiative processes through phonon formation, provides efficient high temperature phosphors for uses in WLED and other applications.

\section{SUMMARY}

In summary, the photoluminescence from $\mathrm{M}_{2} \mathrm{Si}_{5} \mathrm{~N}_{8}$ : $\mathrm{Eu}^{2+}$ phosphors is found to increase substantially with cation disorder introduced by replacing $\mathrm{Sr}$ with a $\left(\mathrm{Ca}_{0.55} \mathrm{Ba}_{0.45}\right)$ mixture of the same average radius. Cation disorder is found to increase quantum efficiency and suppress thermal quenching, with photoluminescent emission increased by $20-26 \%$ across the $25-200{ }^{\circ} \mathrm{C}$ working temperature range for WLED devices. The main influence of the cation disorder is to suppress nonradiative processes through disruption of lattice vibrations, and to create deep traps that release electrons at high temperatures to compensate for thermal quenching. These effects should be general to other host materials and so introduction of high levels of cation disorder is a promising approach for improving the efficiency of luminescent materials with applications in the field of lighting. Suppression of thermal quenching in the special case of a high temperature positional order-disorder phase transition has just been reported in the $\mathrm{Na}_{3-2 \mathrm{x}} \mathrm{Sc}_{2}\left(\mathrm{PO}_{4}\right)_{3}: \mathrm{Eu}_{\mathrm{x}}$ phosphor. ${ }^{33}$

\section{ASSOCIATED CONTENT}

\section{Supporting Information}

Experimental methods, supporting tables and figures are available free of charge via the Internet at http://pubs.acs.org.

\section{AUTHOR INFORMATION}

\section{Corresponding Authors}

rsliu@ntu.edu.tw; j.p.attfield@ed.ac.uk

\section{Chun Che Lin}

Chun Che Lin currently works at the Institute of Organic and Polymeric Materials, National Taipei University of Technology, Taipei 106, Taiwan.

\section{Notes}

The authors declare no competing financial interest.

\section{ACKNOWLEDGMENTS}

This work was supported by the Ministry of Science and Technology of Taiwan (Contract No. MOST 104-2113-M-002-012MY3), EPSRC and STFC, UK. This research used resources at the Spallation Neutron Source, a DOE Office of Science User Facility operated by the Oak Ridge National Laboratory.

\section{REFERENCES}

(1) Hashimoto, T.; Wu, F.; Speck, J. S.; Nakamura, S. Nat. Mater. 2007, 6, 568-571.

(2) Pimputkar, S.; Speck, J. S.; DenBaars, S. P.; Nakamura, S. Nat. Photonics 2009, 3, 180-182.

(3) Lin, C. C.; Liu, R. S. J. Phys. Chem. Lett. 2011, 2, 1268-1277.

(4) Pust, P.; Weiler, V.; Hecht, C.; Tücks, A.; Wochnik, A. S.; Henß, A.-K.; Wiechert, D.; Scheu, C.; Schmidt, P. J.; Schnick, W. Nat. Mater. 2014, 13, 891-896.

(5) Feldmann, C.; Justel, T.; Ronda, C. R.; Schmidt, P. J. Adv. Funct Mater. 2003, 13, 511-516.
(6) Li, G. G.; Tian, Y.; Zhao, Y.; Lin, J. Chem. Soc. Rev. 2015, 44, 8688-8713

(7) Vriens, L.; Acket, G.; Ronda, C. US 5813753 A (2010).

(8) Krames, M. R.; Mueller, G. O.; Mueller-Mach, R. B.; Bechtel, H.H.; Schmidt, P. J. WO 2010131133A1 (2010).

(9) Schlieper, T.; Milius, W.; Schnick, W. Anorg. Allg. Chem. 1995 , $621,1380-1384$.

(10) Zeuner, M.; Pagano, S.; Schnick, W. Angew. Chem. Int. Ed. 2011, 50, 7754-7775.

(11) Xie, R. J.; Hirosaki, N. Sci. Technol. Adv. Mater. 2007, 8, 588600 .

(12) Höppe, H. A. Angew. Chem. Int. Ed. 2009, 48, 3572-3582.

(13) Li, Y. Q.; van Steen, J. E. J.; van Krevel, J. W. H.; Botty, G.; Delsing, A. C. A.; DiSalvo, F. J.; de With, G.; Hintzen, H. T. J. Alloys Compd. 2006, 417, 273-279.

(14) Lee, B.; Lee, S.; Jeong, H. G.; Sohn, K.-S. ACS Comb. Sci. 2011, $13,154-158$.

(15) Piaoa, X.; Horikawa, T.; Hanzawa, H.; Machida, K.-i. J. Electrochem. Soc. 2006, 153, H232-H235.

(16) Zhang, B.; Wang, J.-W.; Hao, L.-Y.; Xu, X.; Agathopoulos, S.; Yin, L.-J.; Wang, C.-M.; Hintzen, H. T. J. Am. Ceram. Soc. 2017, 100, 257-264.

(17) Zhang, C.; Uchikoshi, T.; Xie, R.-J.; Liu, L.; Cho, Y.; Sakka, Y.; Hirosaki, N.; Sekiguchic, T. Phys. Chem. Chem. Phys. 2016, 18, 12494-12504.

(18) Chen, W. T.; Sheu, H. S.; Liu, R. S.; Attfield, J. P. J. Am. Chem. Soc. 2012, 134, 8022-8025.

(19) Wang, S. S.; Chen, W. T.; Li, Y.; Wang, J.; Sheu, H. S.; Liu, R. S. J. Am. Chem. Soc. 2013, 135, 12504-12507.

(20) Rodriguez-Martinez, L. M.; Attfield, J. P. Phys. Rev. B: Condens. Matter. 1996, 54, R15622-R15625.

(21) Attfield, J. P. Cryst. Eng. 2002, 5, 427-438.

(22) Attfield, J. P.; Kharlanov, A. L.; McAllister, J. A. Nature 1998, 394, 157-159.

(23) Sinclair, D. C.; Attfield, J. P. Chem. Commun. 1999, 16, 14971498.

(24) Shannon, R. D. Acta Cryst. 1976, A32, 751-767.

(25) Wu, Y. F.; Chan, Y. H.; Nien, Y. T.; Chen, I. G. J. Am. Ceram. Soc. 2013, 96, 234-240.

(26) Tsai, Y. T.; Chiang, C. Y.; Zhou, W. Z.; Lee, J. F.; Sheu, H. S.; Liu, R. S. J. Am. Chem. Soc. 2015, 137, 8936-8939.

(27) Ruiz-Morales, J. C.; Canales-Vázquez, J.; Savaniu, C.; MarreroLópez, D.; Zhou, W. Z.; Irvine, J. T. S. Nature 2006, 439, 568-571.

(28) Zhang, Y. Q.; Su, Z. X.; Azad, A. K.; Zhou, W. Z.; Irvine, J. T. S. Adv. Energy Mater. 2012, 2, 316-321.

(29) Xie, R.-J.; Hirosaki, N.; Suehiro, T.; Xu, F.-F.; Mitomo, M. Chem. Mater. 2006, 18, 5578-5583.

(30) Zhang, Z. J.; Kate, O. M. t.; Delsing, A. C. A.; Stevens, M. J. H.; Zhao, J. T.; Notten, P. H. L.; Dorenbos, P.; Hintzen, H. T. J. Mater. Chem. 2012, 22, 23871-23876.

(31) Zhang, Z. J.; Kate, O. M. t.; Delsing, A. C. A.; Kolk, E. v. d.; Notten, P. H. L.; Dorenbos, P.; Zhao, J. T.; Hintzen, H. T. J. Mater. Chem. 2012, 22, 9813-9820.

(32) Bhushan, S.; Chukichev, M. V. J. Mater. Sci. Lett. 1988, 7, 319321.

(33) Kim, Y. H.; Arunkumar, P.; Kim, B. Y.; Unithrattil, S.; Kim, E.; Moon, S. H.; Hyun, J. Y.; Kim, K. H.; Lee, D.; Lee, J. S.; Im, W. B. Nat. Mater. 2017, 16, 543-550. 